\title{
Fontes de amido no concentrado de bovinos superprecoces de diferentes classes sexuais
}

\author{
[Sources of starch in the concentrate of young bovines \\ from different sex classes] \\ L.C.V. Itavo ${ }^{1,5}$, A.M. Dias ${ }^{3}$, A.R. Schio ${ }^{2}$, R.G. Mateus ${ }^{1}$, F.F. Silva ${ }^{2,5}$, \\ C.C.B.F. Itavo ${ }^{3}$, E. Nogueira ${ }^{4}$, E.S. Leal ${ }^{2}$ \\ ${ }^{1}$ Universidade Católica Dom Bosco - UCDB - Campo Grande, MS \\ ${ }^{2}$ Universidade Estadual do Sudoeste da Bahia - UESB - Itapetinga, BA \\ ${ }^{3}$ Universidade Federal de Mato Grosso do Sul - UFMS - Campo Grande, MS \\ ${ }^{4}$ Empresa Brasileira de Pesquisa Agropecuária - Embrapa - CPAP - Corumbá, MS \\ ${ }^{5}$ Bolsista de Produtividade do CNPq
}

\begin{abstract}
RESUMO
Objetivou-se avaliar duas fontes de amido (milho ou sorgo) no concentrado e três classes sexuais sobre o consumo de nutrientes, o desempenho e as características da carcaça de bovinos superprecoces. Foram utilizados 30 animais cruzados Beefalo-Nelore, com peso corporal médio inicial de 234,38 $26,17 \mathrm{~kg}$, em delineamento inteiramente ao acaso, em esquema fatorial $2 \times 3$ (duas fontes de amido e três classes sexuais: fêmeas, machos castrados e machos não castrados). O período experimental foi de 224 dias. Na fase inicial (zero-17 semanas), os ganhos de peso total (GPT) e diário (GMD) foram 150,62 e 108,62kg e 1,27 e $0,91 \mathrm{~kg} / \mathrm{dia}$, respectivamente, para milho e sorgo. Na fase final (17-32 semanas), houve efeito da fonte de amido para o peso de carcaça, com médias de 273,00 e 231,95kg, respectivamente, para os tratamentos com milho e sorgo. Houve efeito de classe sexual para GP, GMD e eficiência alimentar, com médias de GP iguais a 98,17, 124,70 e 119,70kg, GMD de 0,93,1,19 e 1,14kg/dia e 8,66, 12,24 e $11,09 \%$, respectivamente, para fêmeas, machos castrados e machos não castrados. Espessura de gordura subcutânea (EGS) apresentou médias de 10,50; 5,97 e 5,51mm, respectivamente, para fêmeas, machos castrados e machos não castrados. Recomenda-se o milho como fonte de amido na fase inicial do confinamento de superprecoces. Na fase final (17-32 semanas), não há distinção entre milho ou sorgo. As fêmeas apresentaram maior EGS, e os machos, castrados e não castrados, apresentaram maior eficiência alimentar na fase final do confinamento.
\end{abstract}

Palavras-chave: castração, eficiência alimentar, novilhas, milho, sorgo

\begin{abstract}
The aim of this study was to evaluate two sources of starch in the concentrate, and three sex classes, on the consumption of nutrients, the performance and carcass characteristics of young bovines in feedlot. Thirty Beefalo-Nellore crossbred with an average initial body weight of $234.38 \pm 26.17 \mathrm{~kg}$ and average age of nine months was used. All animals were maintained in individual bays. A completely randomized design with $2 \times 3$ factorial (two starch source and three sexual categories) was used. The experimental period lasted 224 days (32 weeks). In the initial phase (0-17 weeks) the weight gain (WG) and average daily gain $(A D G)$ were 150.62 and $108.62 \mathrm{~kg}$ and 1.27 and $0.91 \mathrm{~kg} /$ day, respectively, for corn and sorghum. In the final phase (17-32 weeks) the feed efficiency of animals fed with maize was similar to sorghum, with an average of 10.66\%. There was a significant source of starch for carcass weight, averaging 273.00 and $231.95 \mathrm{~kg}$ respectively for the treatments with maize and sorghum. There was a sex
\end{abstract}

Recebido em 14 de fevereiro de 2013

Aceito em 16 de dezembro de 2013

E-mail: itavo@ucdb.br

Apoio financeiro: Fundação de Apoio ao Desenvolvimento do Ensino, Ciência e Tecnologia do Estado de Mato Grosso do Sul FUNDECT (Processo 41/100.144/2006) 
class effect for $W G, A D G$ and feed efficiency, with $W G$ average equal to $98.17,124.70$ and $119.70 \mathrm{~kg}$, average daily gain of 0.93, 1.19 and $1.14 \mathrm{~kg} /$ day and $8.66,12.24$ and $11.09 \%$ respectively for heifers, steers and young bulls. The subcutaneous fat thickness (SFT) showed an average of 10.50, 5.97 and $5.51 \mathrm{~mm}$ for heifers, steers and intact males. In conclusion, the use of corn as a source of starch in the initial phase of the feed for young cattle is recommended. However, in the final stage, there is no distinction between sources of starch in the concentrate, which can be corn or sorghum. Females had higher EGS, while the males, castrated and intact, had higher feed efficiency in the final phase of confinement.

Keywords: castration, corn, feed efficiency, heifer, sorghum

\section{INTRODUÇÃO}

Bovinos superprecoces são confinados ao desmame e abatidos aos 15 meses de idade. Esses animais se apresentam mais eficientes, devido à menor exigência energética de mantença, que proporciona maior energia para ganho. A eficiência no confinamento depende principalmente da dieta, da genética dos animais e da condição ou classe sexual (Paulino et al., 2008).

No Brasil, o milho é a principal fonte energética, entretanto é crescente o uso do sorgo em rações para bovinos. O sorgo apresenta em torno de 90\% do valor energético do milho (Owens et al., 1997), devido à menor digestibilidade do amido (Owens e Zinn, 2005), o que influencia seu valor de mercado. Segundo Rocha Jr. et al. (2003), o sorgo apresenta $88,3 \%$ do valor energético do milho (93,75 vs. $82,82 \%$ de NDT). Essas diferenças são atribuídas às características estruturais do amido, como teor de amilose, distribuição de comprimento das cadeias de amilopectina e cristalinidade no grânulo (Denardin e Silva, 2009). Estruturalmente, o amido é um homopolissacarídeo composto por cadeias de amilose e amilopectina. A amilose é formada por unidades de glicose unidas por ligações glicosídicas $\alpha-1,4$, originando uma cadeia linear. Já a amilopectina é formada por unidades de glicose unidas em $\alpha-1,4$ e $\alpha-1,6$, formando uma estrutura ramificada. As proporções em que essas estruturas aparecem diferem em relação às fontes, às variedades de uma mesma espécie e, ainda que numa mesma variedade, de acordo com o grau de maturação da planta (Eliasson, 2004). Assim, seria interessante o estudo sobre as diferenças de aproveitamento de diferentes fontes de amido no concentrado por bovinos superprecoces.
Ítavo et al. (2006) avaliaram grãos de milho e de sorgo, secos ou ensilados úmidos, para cordeiros em confinamento e concluíram que, em dietas com proporção volumoso:concentrado 50:50, as silagens de grãos úmidos proporcionaram ganho de peso e conversão e eficiência alimentares melhores em relação àquelas contendo grãos secos. Em dietas com proporção volumoso:concentrado 30:70, os grãos de sorgo secos proporcionaram melhor conversão alimentar que os de milho secos e as silagens de grãos úmidos.

A classe (machos ou fêmeas) e a condição sexual (castrados ou não castrados) também têm determinado diferenças no crescimento e na deposição de tecidos corporais (Berg e Butterfield, 1976). Paulino et al. (2008) afirmaram que machos não castrados apresentam desempenho superior e que o sexo influencia fortemente a deposição de gordura. Ítavo et al. (2008) avaliaram os efeitos da castração de bovinos e sugeriram a utilização de animais não castrados por apresentarem desempenhos produtivos e maiores AOL, superiores aos castrados e às fêmeas. Além disso, observaram melhores resultados econômicos em animais não castrados terminados em pastagens abatidos aos 22 meses. No entanto, o efeito de classe sexual e sua interação com diferentes fontes de amido na dieta são poucos conhecidos. Assim, objetivouse avaliar o efeito de fontes de amido no concentrado associado às distintas classes sexuais sobre o desempenho e as características da carcaça de novilhos superprecoces.

\section{MATERIAL E MÉTODOS}

O experimento foi conduzido no Setor de Bovinocultura e no Laboratório de Biotecnologia aplicada à Nutrição Animal da Universidade Católica Dom Bosco - UCDB, em Campo Grande, MS. Foram utilizados 30 bovinos 
cruzados F1 (3/4 Beefalo-1/4 Nelore), com oito meses de idade e média de peso corporal (PC) inicial de 234,38 $26,17 \mathrm{~kg}$, em três classes/condições sexuais, sendo 10 fêmeas, 10 machos castrados com burdizzo ao desmame, com oito meses de idade, e 10 machos não castrados, alojados em baias individuais com piso de chão batido e concreto próximo ao cocho, providas de comedouro e bebedouro, com área total de $27 \mathrm{~m}^{2}$, sendo $9 \mathrm{~m}^{2}$ cobertos. Os animais passaram por um período de adaptação de 30 dias, quando foram identificados, vacinados e vermifugados. No início do experimento, os animais foram previamente pesados e distribuídos aleatoriamente nos tratamentos com diferentes fontes de amido (milho ou sorgo) no concentrado e, posteriormente, pesados a cada 28 dias, em jejum de sólidos por 12 horas.

As dietas eram compostas por milho ou sorgo, como fonte de amido no concentrado, e silagem de milho da planta inteira (Zea mays), na proporção volumoso:concentrado, em base de matéria seca, de 60:40 na fase inicial (entrada no confinamento até $360 \mathrm{~kg}$ de PC) e 50:50 na fase final $(360 \mathrm{~kg}$ de PC até o abate, com $480 \mathrm{~kg}$ de PC). As dietas foram isoproteicas $\mathrm{e}$ isoenergéticas (Tab. 1).

O confinamento experimental teve duração de 224 dias (32 semanas), 119 dias (17 semanas) na fase inicial e 105 dias (15 semanas) na fase final. Os alimentos foram fornecidos, uma vez ao dia (13h), de forma a manter as sobras em torno de $5 \%$ do fornecido, e a água foi fornecida ad libitum. A quantidade ofertada de dieta e as sobras foram registradas diariamente para determinação do consumo de nutrientes das dietas. As amostras dos alimentos fornecidos e das sobras foram secas em estufa com ventilação forçada, a $65^{\circ} \mathrm{C}$ por 72 horas, processadas em moinho tipo Willey com peneira de $1,0 \mathrm{~mm}$ e, posteriormente, submetidas às análises laboratoriais.

Tabela 1. Composição dos concentrados, do volumoso e das dietas totais utilizadas no experimento com base na matéria seca

\begin{tabular}{|c|c|c|c|c|c|c|c|}
\hline \multirow{2}{*}{ Item } & \multicolumn{2}{|c|}{ Concentrados } & \multirow{2}{*}{$\begin{array}{l}\text { Silagem } \\
\text { de milho }\end{array}$} & \multicolumn{2}{|c|}{$\begin{array}{l}\text { Dieta total } \\
\text { Inicial }\end{array}$} & \multicolumn{2}{|c|}{$\begin{array}{l}\text { Dieta total } \\
\text { Final }\end{array}$} \\
\hline & Milho $^{(1)}$ & Sorgo ${ }^{(2)}$ & & Milho & Sorgo & Milho & Sorgo \\
\hline MS (\%) & 88,28 & 89,02 & 40,50 & 59,61 & 59,91 & 64,39 & 64,76 \\
\hline $\mathrm{MO}(\% \mathrm{MS})$ & 94,44 & 94,70 & 95,28 & 94,94 & 95,05 & 94,86 & 94,99 \\
\hline $\mathrm{PB}(\% \mathrm{MS})$ & 18,00 & 18,00 & 7,26 & 11,56 & 11,56 & 12,63 & 12,63 \\
\hline $\mathrm{EE}(\% \mathrm{MS})$ & 2,93 & 2,54 & 2,99 & 2,97 & 2,81 & 2,96 & 2,76 \\
\hline $\mathrm{FDN}(\% \mathrm{MS})$ & 21,87 & 14,57 & 55,68 & 42,16 & 39,24 & 38,77 & 35,13 \\
\hline FDA (\% MS) & 7,09 & 7,81 & 30,80 & 21,32 & 21,60 & 18,94 & 19,31 \\
\hline $\mathrm{CNF}(\% \mathrm{MS})$ & 51,64 & 59,59 & 29,35 & 38,25 & 41,44 & 40,50 & 44,47 \\
\hline $\mathrm{NNP}(\% \mathrm{MS})$ & 0,92 & 0,92 & 41,36 & 25,18 & 25,18 & 21,14 & 21,14 \\
\hline $\mathrm{Ca}(\% \mathrm{MS})$ & 1,50 & 1,50 & 0,30 & 0,78 & 0,78 & 0,90 & 0,90 \\
\hline $\mathrm{P}(\% \mathrm{MS})$ & 0,50 & 0,50 & 0,19 & 0,31 & 0,31 & 0,34 & 0,34 \\
\hline
\end{tabular}

MS = matéria seca; $\mathrm{MO}=$ matéria orgânica; $\mathrm{PB}=$ proteína bruta $(\mathrm{N}$ total x 6,25); $\mathrm{EE}=$ extrato etéreo; FDN = fibra em detergente neutro; FDA = fibra em detergente ácido; $\mathrm{NNP}=$ nitrogênio não proteico (\% do $\mathrm{N}$ total $) ; \mathrm{Ca}=$ cálcio; $\mathrm{P}=$ fósforo. ${ }^{(1)}$ Concentrado com milho $=81,71 \%$ de milho quebrado; $11,28 \%$ de farelo de algodão; $5 \%$ de núcleo mineral e $2 \%$ de ureia pecuária. ${ }^{(2)}$ Concentrado com sorgo $=85,37 \%$ de sorgo moído; $7,63 \%$ de farelo de algodão; $5 \%$ de núcleo mineral e $2 \%$ de ureia pecuária.

As amostras foram avaliadas quanto ao teor de matéria seca (MS), matéria orgânica (MO), proteína bruta $(\mathrm{PB})$, extrato etéreo $(\mathrm{EE})$, cálcio (Ca) e fósforo (P), de acordo com metodologias descritas por Silva e Queiroz (2002). As determinações de FDN e FDA seguiram os métodos descritos por Mertens (2002). Para estimativa dos carboidratos totais (CT), foi utilizada a equação proposta por Sniffen et al.
(1992), como CT = $100-(\mathrm{PB}+\mathrm{EE}+\mathrm{MM})$, e, para estimativa dos carboidratos não fibrosos $(\mathrm{CNF})$, foi usada a equação CNF = CT - FDN.

Área de olho de lombo (AOL), marmoreio (MARM) e espessura de gordura subcutânea (EGS) foram avaliados ao final do experimento, por meio da técnica de ultrassonografia, de acordo com os procedimentos adotados por 
Suguisawa et al. (2006), com acoplamento do transdutor perpendicular ao Longissimus dorsi, entre a $12^{\mathrm{a}}$ e $13^{\mathrm{a}}$ costelas. O equipamento de ultrassonografia utilizado foi o PIEMEDICAL Scanner 200 VET, com transdutor de $3,5 \mathrm{MHz}$ de $18 \mathrm{~cm}$ e uma guia acústica.

Os animais foram abatidos em frigorífico comercial, após jejum de sólidos de 16 horas. Após a retirada das vísceras, as carcaças foram pesadas para obtenção do rendimento de carcaça quente. $\mathrm{O}$ delineamento utilizado foi inteiramente ao acaso, em esquema fatorial $2 \times 3$ (duas fontes de amido - milho e sorgo - e três classes sexuais - fêmeas, machos castrados e machos não castrados), totalizando seis tratamentos, 15 repetições para cada fonte de amido no concentrado e 10 repetições para a classe sexual de fêmeas, 10 repetições para a classe sexual de machos castrados e 10 repetições para a classe sexual de machos não castrados. Utilizou-se o modelo estatístico: Yijk $=\mu+\mathrm{Ai}+\mathrm{Sj}+\mathrm{ASij}+\mathrm{eijk}$, em que: Yijk $=$ observação $\mathrm{k}$, referente ao tratamento com fonte de amido i, associada à classe sexual $\mathrm{j} ; \mu=$ constante geral; $\mathrm{Ai}=$ efeito da fonte de amido no concentrado $\mathrm{i}, \mathrm{i}=1$ e $2 ; \mathrm{Sj}=$ efeito da classe sexual $\mathrm{j}, \mathrm{j}=1, \ldots 3$; VTij = efeito da interação entre fonte de amido i e classe sexual $\mathrm{j}$; e eijk = erro aleatório associado a cada observação Yijk. Os dados foram analisados por meio de análise de variância, e as médias comparadas pelo teste de Tukey, a 5\% de significância.

\section{RESULTADOS E DISCUSSÃO}

A interação fonte de amido $\times$ classe sexual não foi significativa $(\mathrm{P}>0,05)$ para as variáveis estudadas na fase inicial do confinamento (zero a 17 semanas de confinamento). O uso do milho como fonte energética no concentrado permitiu maior consumo em relação ao sorgo, com exceção do consumo de carboidratos não fibrosos (CNF) (Tab. 2), provavelmente devido à presença de tanino e da matriz proteica que envolve os grânulos de amido do sorgo, os quais, com o avanço da idade e a maturidade do grão, reduzem sua digestibilidade. Segundo Van Soest (1994), apesar da semelhança entre o teor de amido nos grãos de sorgo e milho, o amido do sorgo apresenta $25 \%$ de amilose e $75 \%$ de amilopectina, enquanto o amido do grão de milho apresenta $28 \%$ e $72 \%$, respectivamente, o que pode conferir certa vantagem no que diz respeito à digestibilidade do grão de sorgo, devido à maior degradabilidade ruminal da amilose. Passini et al. (2002a) avaliaram milho e sorgo e concluíram que a substituição do grão úmido de milho pelo de sorgo ensilado, nas proporções de $50 \%$ e $100 \%$, diminui linearmente a digestibilidade aparente do amido das dietas. Marcondes et al. (2009) avaliaram a degradabilidade ruminal e detectaram semelhanças entre o milho e o sorgo quanto à fração solúvel (a) da MS, respectivamente, 45,13 e $45,84 \%$, e quanto à fração potencialmente degradável (b): 53,91 e 54,16\%. Entretanto, os autores observaram que há diferenças quanto à taxa de degradação da fração $b$, sendo 0,80 para o milho e 0,40 para o sorgo, fato este que poderia explicar o maior consumo para o tratamento com milho como fonte de amido no concentrado. Não houve efeito de classe sexual para os consumos de nutrientes na fase inicial (Tab. 2).

O consumo de PB na fase inicial do confinamento (zero a 17 semanas) foi maior para os animais alimentados com milho $(0,85 \mathrm{vs}$. $0,81 \mathrm{~kg}$ de $\mathrm{PB} / \mathrm{dia})$. Destaca-se que a presença de tanino no sorgo interferiu negativamente no consumo (Tab. 2). Os animais que receberam milho na fase inicial também consumiram mais FDN $(\mathrm{P}<0,05)$, sem diferença entre classe sexual, com média de $3,00 \mathrm{~kg} / \mathrm{dia}$, valor inferior ao observado por Ítavo et al. (2002), que apresentaram consumo de FDN de $1,5 \%$ do PC $(3,76 \mathrm{~kg})$, obtidos por novilhos Nelore em confinamento que receberam $40 \%$ de concentrado na dieta. Tais diferenças podem ser atribuídas, provavelmente, à qualidade da dieta utilizada e à reduzida idade e peso (<380kg PC) dos animais associadas ao aspecto adstringente do sorgo moído. Ítavo et al. (2002) avaliaram os consumos dos nutrientes de dietas com diferentes níveis de concentrado (20, 40, 60 e 80\%), utilizando milho como fonte energética e os dois níveis de proteína (15 e 18\% PB), associadas ao feno de capim-Tifton 85 como volumoso, em novilhos Nelore não castrados, e observaram, na fase de recria (240-360kg PV), valores máximos de CMS, CMO, CPB e CCT iguais a 7,60; 7,23; 1,$30 ;$ e $5,77 \mathrm{~kg} / \mathrm{dia}$, estimados para 45,94 ; 46,$94 ; 40,91$; e $48,18 \%$ de concentrado, respectivamente, similares aos apresentados na Tab. 2. 
Tabela 2. Médias de consumo de nutrientes e desempenho produtivo de bovinos superprecoces na fase inicial de confinamento, em função da fonte de amido no concentrado e da classe sexual ${ }^{(1)}$

\begin{tabular}{|c|c|c|c|c|c|c|c|c|c|}
\hline \multirow[b]{2}{*}{ Item } & \multicolumn{2}{|c|}{ Fonte de amido } & \multicolumn{3}{|c|}{ Classe sexual } & \multirow[b]{2}{*}{$\mathrm{P}^{(2)}$} & \multirow[b]{2}{*}{$\mathrm{P}^{(3)}$} & \multirow[b]{2}{*}{$\mathrm{P}^{(4)}$} & \multirow[b]{2}{*}{$\begin{array}{l}\text { CV } \\
(\%)\end{array}$} \\
\hline & Milho & Sorgo & Fêmea & $\begin{array}{l}\text { Macho } \\
\text { castrado }\end{array}$ & $\begin{array}{l}\text { Macho } \\
\text { não } \\
\text { castrado }\end{array}$ & & & & \\
\hline \multicolumn{10}{|c|}{ Consumo de nutrientes } \\
\hline CMS (kg/dia) & $7,67 \mathrm{a}$ & $6,99 \mathrm{~b}$ & 7,65 & 7,15 & 7,18 & 0,02 & 0,31 & 0,47 & 9,21 \\
\hline CMO (kg/dia) & $7,28 \mathrm{a}$ & $6,64 b$ & 7,27 & 6,80 & 6,82 & 0,02 & 0,31 & 0,43 & 9,11 \\
\hline CPB (kg/dia) & $0,89 \mathrm{a}$ & $0,81 b$ & 0,88 & 0,82 & 0,830 & 0,02 & 0,31 & 0,39 & 9,11 \\
\hline CEE (kg/dia) & $0,23 \mathrm{a}$ & $0,20 \mathrm{~b}$ & 0,22 & 0,21 & 0,208 & 0,01 & 0,28 & 0,45 & 9,32 \\
\hline CFDN (kg/dia) & $3,23 \mathrm{a}$ & $2,78 \mathrm{~b}$ & 3,15 & 2,94 & 2,93 & 0,01 & 0,27 & 0,38 & 9,43 \\
\hline CFDA (kg/dia) & $1,64 \mathrm{a}$ & $1,50 \mathrm{~b}$ & 1,64 & 1,53 & 1,54 & 0,03 & 0,32 & 0,40 & 9,09 \\
\hline CCNF (kg/dia) & 2,95 & 2,86 & 3,02 & 2,83 & 2,86 & NS & 0,38 & 0,48 & 9,21 \\
\hline $\mathrm{CCa}$ (g/dia) & $59,84 \mathrm{a}$ & $54,50 \mathrm{~b}$ & 59,69 & 55,82 & 55,99 & 0,02 & 0,31 & 0,46 & 9,11 \\
\hline $\mathrm{CP}(\mathrm{g} / \mathrm{dia})$ & $23,78 \mathrm{a}$ & $21,66 \mathrm{~b}$ & 23,72 & 22,19 & 22,25 & 0,02 & 0,31 & 0,44 & 9,11 \\
\hline \multicolumn{10}{|c|}{ Desempenho produtivo } \\
\hline PCI (kg) & 232,60 & 236,16 & 234,33 & 231,80 & 237,00 & 0,45 & 0,47 & 0,44 & 9,89 \\
\hline PCF (kg) & $383,22 \mathrm{a}$ & $344,78 b$ & $371,00 \mathrm{a}$ & $348,90 b$ & $372,10 \mathrm{a}$ & 0,04 & 0,05 & 0,48 & 12,31 \\
\hline GPT (kg) & $150,62 \mathrm{a}$ & $108,62 b$ & $136,67 a$ & $117,10 b$ & $135,10 \mathrm{a}$ & 0,01 & 0,03 & 0,33 & 23,10 \\
\hline GMD (kg/dia) & $1,27 \mathrm{a}$ & $0,91 b$ & $1,15 \mathrm{a}$ & $0,98 b$ & $1,13 \mathrm{a}$ & 0,01 & 0,03 & 0,33 & 23,10 \\
\hline EA $(\%)$ & $16,40 \mathrm{a}$ & $13,05 \mathrm{~b}$ & 14,95 & 13,54 & 15,68 & 0,01 & 0,29 & 0,27 & 20,52 \\
\hline
\end{tabular}

CMS = consumo de matéria seca; $\mathrm{CMO}$ = consumo de matéria orgânica; $\mathrm{CPB}$ = consumo de proteína bruta;

$\mathrm{CEE}=$ consumo de extrato etéreo; $\mathrm{CFDN}=$ consumo de fibra em detergente neutro; $\mathrm{CFDA}=$ consumo de fibra em detergente ácido; $\mathrm{CCNF}=$ consumo de carboidratos não fibrosos; $\mathrm{CCa}=$ consumo de cálcio;

$\mathrm{CP}=$ consumo de fósforo; $\mathrm{PCI}=$ peso corporal inicial; $\mathrm{PCF}=$ peso corporal final no período (zero-17 semanas de confinamento); GPT = ganho de peso total no período (zero-17 semanas de confinamento); GMD = ganho médio diário; $\mathrm{EA}=(\mathrm{GMD} / \mathrm{CMS} * 100)=$ eficiência alimentar

${ }^{(1)}$ Médias seguidas por letras minúsculas distintas na mesma linha diferem pelo teste Tukey $(\mathrm{P}<0,05)$.

${ }^{(2)} \mathrm{P}=$ nível de significância da fonte de amido (milho e sorgo).

${ }^{(3)} \mathrm{P}=$ nível de significância da classe sexual (fêmeas, machos castrados e machos não castrados).

${ }^{(4)} \mathrm{P}$ = nível de significância da interação fonte de amido (milho e sorgo) e a classe sexual (fêmeas, machos castrados e machos não castrados).

Os animais que receberam milho como fonte energética no concentrado apresentaram maiores ganhos de peso (total e diário) e eficiência alimentar $(\mathrm{P}<0,05)$, propiciando maior peso corporal ao final da primeira etapa do confinamento (zero-17 semanas), em média $42,00 \mathrm{~kg}$ mais pesados, o que pode estar relacionado ao menor consumo em decorrência da menor digestibilidade do amido do sorgo (Van Soest, 1994) e à presença de tanino nos grãos, com consequente diminuição do consumo e da digestibilidade da MS total da dieta (Tab. 2), como reportado por Passini et al. (2002a) e Marcondes et al. (2009). O desempenho das fêmeas e dos machos não castrados não diferiu na primeira etapa do confinamento (zero-17 semanas), possivelmente devido à ausência dos efeitos anabólicos dos hormônios sexuais, não interferindo, portanto, no desempenho entre as classes sexuais (Tab. 2). Entretanto, o resultado de desempenho dos castrados foi inferior, provavelmente devido à perda de peso póscastração, ao início do experimento. Pádua et al.
(2004) observaram que machos não castrados apresentam taxa de crescimento em torno de 10 a $20 \%$ superior aos machos castrados, desde que mantidos em condições que lhes permitam expressar seu potencial de crescimento. Tal superioridade também foi citada por Paulino et al. (2008), Freitas et al. (2008) e Ítavo et al. (2008).

$\mathrm{Na}$ fase final do confinamento (17-32 semanas), não houve interação significativa entre fonte de amido no concentrado $\times$ classe/condição sexual. Houve superioridade no consumo de nutrientes nos animais que receberam milho como fonte energética, com exceção do consumo de CNF. Observa-se que o CMS não diferiu entre as classes sexuais, com média de $10,30 \mathrm{~kg} /$ dia (Tab. 3). No experimento de Marcondes et al. (2008), o CMS das classes sexuais também foi igual, porém a conversão alimentar de machos não castrados foi $22 \%$ inferior à de animais castrados e $42 \%$ menor que a de fêmeas, o que pode refletir na lucratividade. $\mathrm{O}$ consumo de 
FDN de aproximadamente $1,0 \%$ do PC é inferior ao $1,7 \%$ estimado por Valadares Filho et al. (2006) e ao $1,8 \%$ observado por Ítavo et al. (2002), como potencial de ingestão de FDN, o que demonstra que o volumoso não limitou o CMS, pois a fibra possui baixa taxa de passagem no rúmen e seu efeito de enchimento ruminal é alto.

Tabela 3. Médias de consumo de nutrientes e desempenho produtivo de bovinos superprecoces na fase final de confinamento, em função da classe sexual e da fonte de amido no concentrado ${ }^{(1)}$

\begin{tabular}{|c|c|c|c|c|c|c|c|c|c|}
\hline \multirow[b]{2}{*}{ Item } & \multicolumn{2}{|c|}{ Fonte de amido } & \multicolumn{3}{|c|}{ Classe sexual } & \multirow[b]{2}{*}{$\mathrm{P}^{(2)}$} & \multirow[b]{2}{*}{$\mathrm{P}^{(3)}$} & \multirow[b]{2}{*}{$\mathrm{P}^{(4)}$} & \multirow[b]{2}{*}{$\begin{array}{l}\mathrm{CV} \\
(\%)\end{array}$} \\
\hline & Milho & Sorgo & Fêmea & $\begin{array}{l}\text { Macho } \\
\text { castrado }\end{array}$ & $\begin{array}{c}\text { Macho } \\
\text { não } \\
\text { castrado }\end{array}$ & & & & \\
\hline \multicolumn{10}{|c|}{ Consumo de nutrientes } \\
\hline CMS (kg/dia) & $10,68 \mathrm{a}$ & $9,89 \mathrm{~b}$ & 10,73 & 9,82 & 10,33 & 0,04 & 0,16 & 0,23 & 8,72 \\
\hline CMO (kg/dia) & $10,15 \mathrm{a}$ & $9,40 \mathrm{~b}$ & 10,19 & 9,33 & 9,81 & 0,04 & 0,15 & 0,22 & 8,67 \\
\hline CPB (kg/dia) & $1,24 \mathrm{a}$ & $1,14 \mathrm{~b}$ & 1,24 & 1,13 & 1,19 & 0,04 & 0,15 & 0,23 & 8,68 \\
\hline CEE (kg/dia) & $0,317 \mathrm{a}$ & $0,281 b$ & 0,313 & 0,286 & 0,298 & 0,01 & 0,16 & 0,34 & 9,03 \\
\hline CFDN (kg/dia) & $4,51 \mathrm{a}$ & $3,93 b$ & 4,42 & 4,03 & 4,20 & 0,04 & 0,32 & NS & 9,17 \\
\hline CFDA (kg/dia) & 2,28 & 2,13 & 2,30 & 2,10 & 2,22 & 0,07 & 0,15 & 0,21 & 8,63 \\
\hline CCNF (kg/dia) & 4,11 & 4,05 & 4,23 & 3,88 & 4,12 & 0,46 & 0,14 & 0,13 & 8,58 \\
\hline $\mathrm{CCa}$ (g/dia) & $83,38 \mathrm{a}$ & $77,18 b$ & 83,70 & 76,60 & 80,53 & 0,04 & 0,15 & 0,23 & 8,68 \\
\hline $\mathrm{CP}$ (g/dia) & $33,14 \mathrm{a}$ & $30,67 \mathrm{~b}$ & 33,27 & 30,44 & 32,01 & 0,04 & 0,15 & 0,23 & 8,68 \\
\hline \multicolumn{10}{|c|}{ Desempenho produtivo } \\
\hline PCI (kg) & $383,22 \mathrm{a}$ & $344,78 b$ & $371,00 \mathrm{a}$ & $348,90 b$ & $372,10 \mathrm{a}$ & 0,04 & 0,04 & 0,48 & 12,31 \\
\hline $\mathrm{PCF}(\mathrm{kg})$ & $501,13 a$ & $455,24 b$ & $469,17 \mathrm{~b}$ & $473,60 \mathrm{~b}$ & $491,80 \mathrm{a}$ & 0,03 & 0,04 & 0,22 & 9,90 \\
\hline GP (kg) & 117,91 & 110,47 & $98,17 \mathrm{~b}$ & $124,70 \mathrm{a}$ & $119,70 \mathrm{a}$ & 0,35 & 0,03 & 0,20 & 17,33 \\
\hline GMD (kg/dia) & 1,12 & 1,05 & $0,93 b$ & $1,19 \mathrm{a}$ & $1,14 \mathrm{a}$ & 0,39 & 0,03 & 0,20 & 17,33 \\
\hline $\mathrm{EA}(\%)$ & 10,60 & 10,72 & $8,66 \mathrm{~b}$ & $12,24 \mathrm{a}$ & $11,09 \mathrm{ab}$ & 0,44 & 0,01 & 0,20 & 18,83 \\
\hline
\end{tabular}

$\mathrm{CMS}$ = consumo de matéria seca; $\mathrm{CMO}=$ consumo de matéria orgânica; $\mathrm{CPB}=$ consumo de proteína bruta;

$\mathrm{CEE}$ = consumo de extrato etéreo; $\mathrm{CFDN}=$ consumo de fibra em detergente neutro; $\mathrm{CFDA}=$ consumo de fibra em detergente ácido; $\mathrm{CCNF}=$ consumo de carboidratos não fibrosos; $\mathrm{CCa}=$ consumo de cálcio;

$\mathrm{CP}=$ consumo de fósforo $\mathrm{PCI}=$ peso corporal inicial $\mathrm{PCF}=$ peso corporal final (ao abate);

GPT = ganho de peso total no período (17-32 semanas de confinamento); GMD = ganho médio diário; EA = $(\mathrm{GMD} / \mathrm{CMS} * 100)=$ eficiência alimentar.

${ }^{(1)}$ Médias seguidas por letras minúsculas distintas na mesma linha diferem pelo teste de Tukey $(\mathrm{P}<0,05)$.

${ }^{(2)} \mathrm{P}=$ nível de significância da fonte de amido (milho e sorgo).

${ }^{(3)} \mathrm{P}=$ nível de significância da classe sexual (fêmeas, machos castrados e machos não castrados).

${ }^{(4)} \mathrm{P}=$ nível de significância da interação fonte de amido (milho e sorgo) e a classe sexual (fêmeas, machos castrados e machos não castrados).

Houve efeito da classe sexual para o peso corporal final (PCF). Os machos não castrados apresentaram superioridade de peso ao abate de $22,63 \mathrm{~kg}$ sobre as fêmeas e $18,20 \mathrm{~kg}$ sobre os castrados (Tab. 3). Em razão de as fêmeas apresentarem taxa de maturação mais pronunciada que os machos, a capacidade de consumo e desempenho das fêmeas diminui com o aumento do peso e da idade, uma vez que a gordura exerce influência direta, por limitações físicas impostas pela gordura abdominal, e indiretas sobre a ingestão alimentar, pela secreção de leptina pelos adipócitos, hormônio que tem sido correlacionado a reduções no consumo (Nkrumah et al., 2005). O crescimento de fêmeas diferencia-se dos machos pela composição e distribuição do ganho de peso de corpo vazio entre os tecidos. A diferença mais pronunciada está na composição da carcaça, em razão das variações no processo de acabamento, evidenciada pelos resultados elevados de EGS (Tab. 4). Novilhas atingem a maturidade precocemente em comparação aos machos, portanto entram mais cedo na fase de deposição de gordura e apresentam menor peso de carcaça em comparação a novilhos (Berg e Butterfield, 1976). Não houve efeito da fonte de amido sobre o ganho de peso (GP) e o ganho médio diário (GMD), com médias de $114,19 \mathrm{~kg}$ e $1,09 \mathrm{~kg} / \mathrm{dia}$, respectivamente, o que pode estar relacionado à composição de ganho dos animais superprecoces confinados, na fase final do confinamento (Tab. 3). Estes resultados estão em concordância com os de Igarasi et al. (2008), que observaram desempenho semelhante de bovinos jovens $(1,42 \mathrm{~kg} / \mathrm{dia})$, confinados por 172 dias, 
alimentados com diferentes ingredientes energéticos (milho ou sorgo).

As médias de GMD deste ensaio são inferiores a $1,24 \mathrm{~kg} /$ dia encontrado por Restle e Vaz (2000), ao trabalharem com novilhos cruzados castrados e terminados em confinamento, e a $1,44 \mathrm{~kg} / \mathrm{dia}$ encontrado por Perotto et al. (2000), que avaliaram bovinos não castrados alimentados com silagem de milho à vontade e concentrado à base de milho e farelo de soja a $1 \%$ do PC, ambos com animais cruzados (Charolês). No sistema de produção superprecoce, é preconizado um ganho médio diário não inferior a $1,2 \mathrm{~kg} / \mathrm{dia}$ (Passini et al., 2002b), fato que não foi observado, o que pode estar relacionado à capacidade genética dos animais Beefalo-Nelore. Devido às semelhanças entre GMD e CMS, a eficiência alimentar não diferiu em relação à fonte de amido no concentrado, com médias de 10,66\%. Também Ítavo et al. (2006) não encontraram efeito da fonte de amido (milho ou sorgo) para a eficiência alimentar de cordeiros confinados.

$\mathrm{Na}$ fase final do confinamento (17-32 semanas), os machos (castrados e não castrados) apresentaram resultados superiores aos das fêmeas, com médias de GP iguais a 98,17, 124,70 e 119,70kg; GMD de 0,93, 1,19 e $1,14 \mathrm{~kg} / \mathrm{dia} ; \quad$ e $8,66,12,24$ e $11,09 \%$, respectivamente, para fêmeas, machos castrados e machos não castrados (Tab. 3). Os machos apresentaram melhor eficiência alimentar, em média $25,73 \%$ superior a das fêmeas. Resultados de pesquisa mostraram que animais não castrados cresceram mais rapidamente $\mathrm{e}$ utilizaram o alimento mais eficientemente que os castrados e as fêmeas (Vittori et al., 2007). Também Marcondes et al. (2008) apresentaram valores de $22 \%$ de superioridade entre as classes sexuais. Resultados semelhantes foram apresentados por Coutinho Filho et al. (2006), que avaliaram machos não castrados e fêmeas com idades e pesos médios iniciais de 12 e 13 meses e 266 e $251 \mathrm{~kg}$, respectivamente. As médias de GMD foram 1,80 e 1,22kg/animal/dia; a conversão alimentar, de 5,61 e 7,18; o rendimento de carcaça, de 55,61 e 52,75\%; e a ingestão de MS, de 10,08 e $8,87 \mathrm{~kg}$ MS/dia, respectivamente, para machos não castrados e fêmeas. A condição sexual é um dos fatores determinantes da composição do ganho de peso, devido às influências da ação hormonal. Assim, bovinos não castrados produzem mais proteína por unidade de energia digestível do que os castrados. Por isso, é provável que dietas com maior teor de proteína pudessem ter proporcionado maiores GP e GMD a esses animais na fase final do confinamento (17-32 semanas), correspondente ao intervalo de peso corporal entre 360 e $480 \mathrm{~kg}$, com observação de maior ganho de peso para machos castrados e não castrados em relação às fêmeas $(p=0,03)$. No experimento de Silva et al. (2002), com bovinos Nelore não castrados, em confinamento, a dieta com 18\% de PB propiciou, aos novilhos, 22,1 e $22,6 \%$ a mais de ganho de peso na recria $(240$ aos 360kg PV) e na engorda (360 aos 460kg PV), respectivamente, comparada à dieta com $15 \%$ de $\mathrm{PB}$.

Não foram observadas diferenças para rendimento de carcaça (RC), área de olho de lombo (AOL) e marmoreio (MARM), com médias de $54,02 \%, 63,99 \mathrm{~cm}^{2}$ e 2,69 pontos (Tab. 4), respectivamente, por estas serem mais influenciadas pela genética e pelas classes sexuais do que pela dieta.

Conforme Metz et al. (2009), existem moduladores do crescimento que controlam o metabolismo, a síntese e degradação proteica e energética, assim como o consumo para que o animal mantenha a retenção de tecido magro ou o ganho peso dentro de certos limites. Os animais do tratamento milho apresentaram maior peso de carcaça (PCARC), 41,05kg a mais do que os animais que receberam sorgo como fonte de amido do concentrado, o que pode ser explicado pelo ganho de peso da fase inicial (zero a 17 semanas). A EGS também foi superior para animais alimentados com milho como fonte energética no concentrado, o que pode estar relacionado ao efeito antinutricional do sorgo, o qual, além de prejudicar o ganho de peso, diminui a deposição de gordura subcutânea nesta fase. Não houve efeito da classe sexual para a maioria das características da carcaça dos bovinos supreprecoces, com exceção da EGS $(\mathrm{P}<0,05)$, com médias de 10,50; 5,97 e 5,51mm, respectivamente, para fêmeas, machos castrados e machos não castrados. Paulino et al. (2008) afirmaram que o sexo influencia fortemente a deposição de gordura da carcaça, pois machos não castrados são mais eficientes em crescimento muscular e apresentam carcaças mais magras que a de machos castrados e fêmeas. 
Tabela 4. Médias de características de carcaça de bovinos superprecoces, em função da classe sexual e da fonte de amido no concentrado ${ }^{(1)}$

\begin{tabular}{|c|c|c|c|c|c|c|c|c|c|}
\hline \multirow[b]{2}{*}{ Item } & \multicolumn{2}{|c|}{ Fonte de amido } & \multicolumn{3}{|c|}{ Classe sexual } & \multirow[b]{2}{*}{$\mathrm{P}^{(2)}$} & \multirow[b]{2}{*}{$\mathrm{P}^{(3)}$} & \multirow[b]{2}{*}{$\mathrm{P}^{(4)}$} & \multirow[b]{2}{*}{$\begin{array}{l}\mathrm{CV} \\
(\%)\end{array}$} \\
\hline & Milho & Sorgo & Fêmea & $\begin{array}{c}\text { Macho } \\
\text { castrado }\end{array}$ & $\begin{array}{c}\text { Macho } \\
\text { não } \\
\text { castrado }\end{array}$ & & & & \\
\hline PCARC (kg) & $273,00 \mathrm{a}$ & $231,95 \mathrm{~b}$ & 239,73 & 254,25 & 263,46 & 0,00 & 0,35 & 0,25 & 12,16 \\
\hline $\mathrm{RC}(\%)$ & 54,50 & 53,55 & 54,89 & 53,56 & 53,62 & 0,17 & 0,26 & 0,45 & 3,09 \\
\hline $\operatorname{AOL}\left(\mathrm{cm}^{2}\right)$ & 65,41 & 62,58 & 64,41 & 59,93 & 67,65 & 0,30 & 0,05 & 0,30 & 10,42 \\
\hline EGS (mm) & $8,52 \mathrm{a}$ & $6,14 \mathrm{~b}$ & $10,50 \mathrm{a}$ & $5,97 \mathrm{~b}$ & $5,51 b$ & 0,01 & 0,01 & 0,06 & 28,09 \\
\hline $\begin{array}{l}\text { MARM } \\
\text { (pontos) }\end{array}$ & 2,39 & 3,00 & 3,42 & 2,25 & 2,42 & 0,15 & 0,09 & 0,12 & 38,71 \\
\hline
\end{tabular}

$\mathrm{RC}=$ rendimento de carcaça; $\mathrm{PCARC}=$ peso da carcaça quente; $\mathrm{AOL}=$ área de olho de lombo;

MARM = marmoreio; EGS = espessura de gordura subcutânea.

${ }^{(1)}$ Médias seguidas por letras minúsculas distintas na mesma linha diferem pelo teste de Tukey $(\mathrm{P}<0,05)$

${ }^{(2)} \mathrm{P}=$ nível de significância da fonte de amido (milho e sorgo).

${ }^{(3)} \mathrm{P}=$ nível de significância da classe sexual (fêmeas, machos castrados e machos não castrados).

${ }^{(4)} \mathrm{P}=$ nível de significância da interação fonte de amido (milho e sorgo) e a classe sexual (fêmeas, machos castrados e machos não castrados).

\section{CONCLUSÕES}

O milho como fonte de amido no concentrado proporcionou maior consumo, melhor eficiência alimentar, maior peso de carcaça e espessura de gordura subcutânea dos animais quando comparado ao sorgo, independentemente da classe sexual. Machos (castrados e não castrados) apresentaram eficiência alimentar $25 \%$ superior a das fêmeas, que apresentaram maior espessura de gordura subcutânea.

\section{REFERÊNCIAS}

BERG, R.T.; BUTTERFIELD, R.M. New concepts of cattle growth. 1.ed. Sydney: Sydney University Press, 1976. 240p.

COUTINHO FILHO, J.L.V.; PERES, R.M.; JUSTO, C.L. Produção de carne de bovinos contemporâneos, machos e fêmeas, terminados em confinamento. Rev. Bras. Zootec., v.35, p.2043-2049, 2006.

DENARDIN, C.C.; SILVA, L.P. Estrutura dos grânulos de amido e sua relação com propriedades físico-químicas. Cienc. Rural, v.39, p.945-954, 2009.

ELIASSON, A.C. Starch in food - Structure, function and applications. New York: Boca Raton, CRC, 2004. 605p.
FREITAS, A.K.; RESTLE, J.; PACHECO, P.S. et al. Características de carcaças de bovinos Nelore inteiros vs castrados em duas idades, terminados em confinamento. Rev. Bras. Zootec., v.37, p.1055-1062, 2008.

IGARASI, M.S.; ARRIGONI, M.B.; SOUZA, A.A. et al. Desempenho de bovinos jovens alimentados com dietas contendo grão úmido de milho ou sorgo. Rev. Bras. Zootec., v.37, p.513519, 2008.

ÍTAVO, L.C.V.; DIAS, A.M.; ÍTAVO, C.C.B.F. et al. Desempenho produtivo, características de carcaça e avaliação econômica de bovinos cruzados, castrados e não-castrados, terminados em pastagens de Brachiaria decumbens. Arq. Bras. Med. Vet. Zootec., v.60, p.1157-1165, 2008.

ÍTAVO, C.C.B.F.; MORAIS, G.M.; ÍTAVO, L.C.V. et al. Efeitos de diferentes fontes de concentrado sobre o consumo e a produção de cordeiros na fase de terminação. Rev. Bras. Zootec., v.35, p.139-146, 2006.

ÍTAVO, L.C.V.; VALADARES FILHO, S.C.; SILVA, F.F. et al. Níveis de concentrado e proteína bruta na dieta de bovinos Nelore nas fases de recria e terminação: consumo e digestibilidade. Rev. Bras. Zootec., v.31, p.10331041, 2002. 
MARCONDES, M.I.; VALADARES FILHO, S.C.; DETMANN, E. et al. Degradação ruminal e digestibilidade intestinal da proteína bruta de alimentos para bovinos. Rev. Bras. Zootec., v.38, p.2247-2257, 2009.

MARCONDES, M.I.; VALADARES FILHO, S.C.; PAULINO, P.V.R. et al. Consumo e desempenho de animais alimentados individualmente ou em grupo e características de carcaça de animais Nelore de três classes sexuais. Rev. Bras. Zootec., v.37, p.2243-2250, 2008.

MERTENS, D.R. Gravimetric determination of amylase treated neutral detergent fiber in feeds with refluxing in beakers or crucibles: Collaborative study. J. AOAC Int., v.85, p.12121240, 2002.

METZ, P.A.M.; MENEZES, L.F.G.; ARBOITTE, M.Z. et al. Influência do peso ao início da terminação sobre as características de carcaça e da carne de novilhos mestiços Nelore $\times$ Charolês. Rev. Bras. Zootec., v.38, p.346-353, 2009.

NKRUMAH, J.D.; LI, C.; YU, J. et al. Polymorphisms in the bovine leptin promoter associated with serum leptin concentration, growth, feed intake, feeding behaviour, and measures of carcass merit. J. Anim. Sci., v.83, p.20-28, 2005.

OWENS, F.N.; SECRIST, D.S.; HILL, W.J. et al. The effect of grain source and grain processing on performance of feedlot cattle: a review. J. Anim. Sci., v.75, p.868-879, 1997.

OWENS, F.N.; ZINN, R. Corn grain for cattle: influence of processing on site and extent of digestion. In: Southwest Nutrition Conference, 2005. El Centro, CA. Proceedings... El Centro: Desert Research Center, University of California, 2005. p.86-112.

PÁDUA, J.T.; MAGNABOSCO, C.U.; SAINZ, R.D. et al. Genótipo e condição sexual no desempenho e nas características de carcaça de bovinos de corte superjovens. Rev. Bras. Zootec., v.33, p.2330-2342, 2004.

PASSINI, R.; SILVEIRA, A.C.; RODRIGUES, P.H.M. et al. Digestibilidade de dietas a base de grão úmido de milho ou de sorgo ensilados. Acta Sci. Anim. Sci., v.24, p.1147-1154, 2002a.
PASSINI, R.; SILVEIRA, A.C.; TITTO, E.A.L. et al. Silagem de grãos úmidos de milho e de sorgo e níveis proteicos sobre desempenho e características da carcaça de novilhos superprecoces. Acta Sci. Anim. Sci., v.24, p.1133-1140, 2002b.

PAULINO, P.V.R.; VALADARES FILHOS, S.C.; DETMANN, E. et al. Desempenho produtivos de bovinos Nelore de diferentes classes sexuais alimentados com dietas contendo dois níveis de oferta de concentrado. Rev. Bras. Zootec., v.37, p.1079-1087, 2008.

PEROTTO, D.; MOLETTA, J.L.; OLIVEIRA, J.E.P. et al. Consumo e conversão alimentar de machos bovinos inteiros Charolês, Caracu e cruzamentos recíprocos em confinamento. Rev. Bras. Zootec., v.29, p.108-116. 2000.

RESTLE, J.; VAZ, F.N. Aspectos qualitativos da carcaça e da carne de machos Hereford, inteiros ou castrados, abatidos aos quatorze meses. Rev. Bras. Zootec., v.29, p.1894-1901, 2000.

ROCHA JUNIOR, V.R.; VALADARES FILHO, S.C.; BORGES, A.M. et al. Determinação do valor energético de alimentos para ruminantes pelo sistema de equações. Rev. Bras. Zootec., v.32, p.473-479, 2003.

SILVA, D.J.; QUEIROZ, A.C. Análise de alimentos: Métodos químicos e biológicos. Universidade Federal de Viçosa: Viçosa, 2002. 235p.

SILVA, F.F.; VALADARES FILHO, S.C.; ÍTAVO, L.C.V. et al. Consumo, desempenho, características de carcaça e biometria do trato gastrintestinal e dos órgãos internos de novilhos Nelore recebendo dietas com diferentes níveis de concentrado e proteína. Rev. Bras. Zootec., v.31, p.1849-1864, 2002.

SNIFFEN, C.J.; O'CONNOR, J.D.; VAN SOEST, P.J. et al. A net carbohydrate and protein system for evaluating cattle diets: II. Carbohydrate and protein availability. J. Anim. Sci., v.70, p.3562-3577, 1992.

SUGUISAWA, L.; MATTOS, W.R.S.; SOUZA, A.A. et. al. Ultra-sonografia para predição da composição da carcaça de bovinos jovens. Rev. Bras. Zootec., v.35, p.177-185, 2006. 
VALADARES FILHO, S.C.; MAGALHÃES, K.A.; ROCHA JÚNIOR, V.R. Exigências nutricionais de zebuínos e tabelas de composição de alimentos $B R$-corte. 1.ed. Viçosa. Universidade Federal de Viçosa, UFV, DZO, 2006. 142p.

VAN SOEST, P.J. Nutritional Ecology of the Ruminant. Comstock Publ. Assoc. Ithaca, 1994. $476 \mathrm{p}$.
VITTORI, A.; GESUALDI JUNIOR, A.; QUEIROZ, A.C. et al. Desempenho produtivo de bovinos de diferentes grupos raciais, castrados e não castrados, em fase de terminação. Arq. Bras. Med. Vet. Zootec., v.59, p.1263-1269, 2007. 